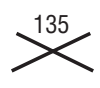

\title{
A retórica dos resultados na comunicação da ciência
}

António Fernando Cascais*

\section{Resumo}

A retórica dos resultados é uma questão que diz respeito sobretudo aos divulgadores, mais do que aos públicos. Consiste em representar a actividade científica pelos seus produtos, subsumir os processos científicos à consecução finalista e cumulativa de resultados e isolar exclusivamente como resultados aqueles que são avaliados a posteriori como êxitos de aplicação. Tal implica ignorar a actividade científica enquanto processo, anular o papel do erro produtivo na tomada de decisão e nas escolhas científicas e assimilar fins a resultados, com a exclusão dos resultados fortuitos, inesperados ou adversos. A retórica dos resultados é efeito de censura positiva da iliteracia que a dinâmica tecnocientífica naturalmente segrega. Há que afirmar que a tecnociência se encontra em condições de disponibilizar meios, melhor do que produzir resultados, contra a retórica que deixa sem resposta o facto da produção de resultados inesperados, indesejáveis e incontroláveis. A retórica dos resultados contribui para a presunção da auto-suficiência científica e pode ser também entendida como ilusão de controlo da dinâmica imparável da tecnociência.

Palavras-chave: retórica; resultados; comunicação da ciência

\section{Introdução: da crise do modelo linear à retórica dos resultados}

A crise do modelo linear que inicialmente dominou a teoria e as práticas da comunicação da ciência possibilitou a emergência de um modelo de interacção acerca do qual as discussões prosseguem. Um tema a que nelas se alude tão frequente quanto superficialmente é o da representação da ciência, e da correspondente percepção pública desta, pelos resultados que ela produz, de preferência ao processo pelo qual se chega a eles. Com efeito, está em vias de se tornar um lugar-comum afirmar que a comunicação da ciência privilegia a apresentação dos resultados dela em detrimento da exposição do processo científico. Por outro lado, não se esclarece se esse envie-

\footnotetext{
* Departamento de Ciências da Comunicação, Faculdade de Ciências Sociais e Humanas, Universidade de Lisboa. E-mail: afcascais@netcabo.pt.
} 
samento é exclusivo, ou predominante, do modelo linear, ou se de algum modo se mantém no modelo de interacção da ciência com o(s) seu(s) público(s).

Para levarmos esta indagação a bom termo, será conveniente principiarmos por recordar aquilo que caracteriza o modelo linear e a superação dele. Nesse modelo, o cientista é visto como produtor de conhecimento que seria simplificado por um mediador (por exemplo, o jornalista) e transmitido unidireccionalmente ao público, percebido como um passivo consumidor de conhecimento. Esta concepção presume a superioridade do conhecimento científico e a sua completa separação do senso comum (Felt, 2000b: 10). Pode dizer-se que tal modelo se foi lentamente sedimentando desde o século XIX, até encontrar uma formulação explícita no programa da 'Public Understanding of Science' da Royal Society inglesa, em 1985 (Royal Society, 1985).

No epicentro da polémica conceptual em que foi posto em causa o modelo linear encontra-se a questão da demarcação - ou, será melhor dizer, de sucessivas demarcações que se sobrepõem - entre o que é e o que não é ciência, entre literacia (dos cientistas) e iliteracia (dos leigos), entre o domínio da ciência e o domínio público não-científico, a vulgarização começou a ser cada vez mais entendida como a negociação do sentido e sublinhou-se que ela, juntamente com o próprio conhecimento vulgar, alimentava, em retorno, o processo de produção de conhecimento científico, assim se repercutindo na dimensão cognitiva da própria ciência (Felt, 2000b:11).

A reflexão crítica da qual surge o modelo de interacção dos cientistas, dos divulgadores e dos públicos irá sublinhar que essa interacção não deve ser entendida como cooperação, mas sobretudo como negociação e, precisamente, na medida em que aquelas demarcações, longe de se manterem estáveis ou de poderem estabilizar-se através de consensos, são antes permanentemente reconstruídas num processo de dissensão e conflito que incide, em primeiro lugar, sobre quem tem autoridade para discutir os próprios critérios de demarcação. Ou, o que é o mesmo, sobre quem, em última análise é admissível à própria discussão. 'The legitimation to claim expertise is at stake. Only by drawing frontiers, by barricading the science system and regulating access to it, can the power of expertise be kept in the hands of scientists (and some policy-makers)' (Felt, 2000b: 10).

Começa a ser do conhecimento geral, e a impor-se, o conceito de trabalho de fronteira ('boundary work') que, nas palavras de Gieryn (1994: 394), diz respeito ao seguinte: 'when, how, and to what ends the boundaries of science are drawn and defended in natural settings often distant from laboratories and professional journals'. Sendo o trabalho de fronteira precipitado por disputas acerca da credibilidade (Gieryn, 1999:340), o que está sobremaneira em causa é a autoridade cognitiva, mas também ética, da ciência.

A partir deste contexto, trata-se, então, de esclarecer aquilo que entendemos por retórica dos resultados.

\section{A retórica dos resultados}

Em essência, a retórica dos resultados consiste em: a) representar a actividade científica pelos seus produtos; b) reduzir os processos científicos à obtenção finalista e 
cumulativa de resultados; e c) isolar exclusivamente como resultados aqueles que são avaliados a posteriori como êxitos de aplicação.

Tal passa implicitamente por: a) ignorar a actividade científica enquanto processo, que, ao mesmo tempo que procede pelo cumprimento protocolar de critérios a priori de rigor metodológico da investigação, progride de modo não linear, errático e tenteante - que o mesmo é dizer, branquear a revisibilidade intrínseca a todo o conhecimento científico e a historicidade inerente ao perseguir de interesses cognitivos, variáveis temporal e espacialmente, a ponto de se tornarem incompatíveis ou mutuamente exclusivos; b) anular o papel do erro criativo (Feyerabend, 1981, 1991; Lakatos, 1998, 1999) na tomada de decisão e nas escolhas científicas, de tal modo que o sucesso da obtenção de resultados é atribuível ao rigor da concepção metodológica - o que implica a necessária eliminação do resto (o racionalmente inexplicável, o estatisticamente excepcional) que excede o domínio de rigor delimitado pelo método, tido por subproduto espúrio dele, em vez de marca dos seus limites de validade; c) provocar um efeito de censura do processo de produção de conhecimento científico: quer como produtor de riscos, na medida em que promove a ilusão do controlo do risco tecnocientífico, quer como disponibilizador de meios, na medida em que assimila fins (aquilo que se pretende obter à partida) a resultados (aquilo que realmente se obtém no termo do processo), definindo retrospectivamente os primeiros em função dos segundos e identificando exclusivamente os resultados do processo científico aqueles que são avaliados como positivos, com a exclusão dos resultados fortuitos, inesperados ou adversos.

Ao dizermos que consiste nisto, pretendemos dizer que a retórica dos resultados não se refere apenas a cada um destes aspectos tomado por si só, mas ao somatório deles. Com efeito, por um lado, nenhum bastaria para a definir em toda a sua extensão, e por outro lado, cada um deles é correlato dos outros, pelo que nunca aparece isolado, ainda que por vezes algum deles, em casos concretos, possa surgir somente de maneira informulada. Imprescindível é aqui notar, porém, que não se trata de fazer uma denúncia do que seria uma ocultação premeditada do cientista, um embuste do divulgador, um efeito perverso da passividade do público leigo, iliterato. Não se trata de desmascarar uma censura que agiria negativamente pela ocultação, pela negação ou pelo disfarce. Não é mentira que a ciência produza resultados, nem sequer é mentira que persiga ela legítimos móbeis cognitivos na sua procura de conhecimento, independentemente da percepção que os públicos possam ter das suas próprias necessidades e interesses. Como não é mentira que o rigor protocolar da empresa tecnocientífica só seria pleno, e logo, idealmente, acessível a um público leigo se este próprio pudesse tornar-se cientista. $\mathrm{Na}$ verdade, é precisamente isto que permite asseverar que '[l]e discours de vulgarisation constitue un exemple de communication confrontée à ses limites' (Jeanneret, 1994: 83).

Para que possamos ter uma compreensão cabal e frutífera daquilo que significa a retórica dos resultados, é imprescindível situá-la num contexto hermenêutico mais vasto, que englobe a condição logotécnica do saber moderno, a tradição de auto-regulação paritária das comunidades científicas e a retórica científica que preexiste à 
própria comunicação da ciência, antes de concluirmos, contextualizando a retórica dos resultados na (i)literacia intrínseca à dinâmica tecnocientífica.

\section{A condição logotécnica do saber moderno}

As condições últimas de existência da retórica dos resultados, há que as encontrar bem antes da comunicação da ciência, na própria índole da tecnociência moderna, que muito a distancia da tekne grega. A nossa reflexão é aqui claramente devedora da descrição da natureza da técnica moderna como tecnociência, em Gilbert Hottois (1984a, 1984b, 1992, 1996, 1999), por sua vez devedor de Martin Heidegger e Hans Jonas. A retórica dos resultados é afim da submissão do rigor teórico da antiga scientia contemplativa à eficácia tecnológica que caracteriza a tecnociência moderna. Nisto consiste o carácter logotécnico da ciência moderna, a qual deixou de aferir o seu rigor da descrição integral e exacta dos estados de coisas que compõem o real para passar a inferi-lo da sua capacidade de alterar eficazmente os estados de coisas, isto é, de manipular o real. O que de modo nenhum significa que tenha sido abandonada a pretensão de descrever integralmente o real, de elaborar uma ontologia; ela passou antes a ser deduzida da eficácia manipuladora da técnica, o que implica que as actuais descrições científicas dos estados de coisas sejam descrições dos efeitos da própria alteração tecnocientífica dos estados de coisas. À antiga ontologia sucedeu deste modo uma ontotecnologia, que só é uma teoria do real na medida em que é uma teoria do real alterado e que só é uma descrição dos estados de coisas na medida em que é uma teoria da acção transformadora desses estados de coisas.

Mais explicitamente: a ciência moderna é ciência porque faz, ao contrário de tudo o que ela não é e que não é ela; faz com que resulte, faz ocorrer, faz com que seja, de tal modo que onde a scientia contemplativa tinha por correlato a estabilidade do real a contemplar, a tecnociência tem por correlato a plasticidade do objecto a manipular. Ora, precisamente, onde a estabilidade intersubjectiva do objecto (vulgo: objectividade) era garantia de segurança na concepção ingénua do conhecimento científico, mas que entrou em crise com a revolução relativista e quântica, a nova estabilidade intersubjectiva do resultado tecnocientífico vem restaurar a antiga segurança ingénua perdida. Por outras palavras, se já não podemos confiar num real que só aparentemente é estável, a renovada eficácia da transformação dele vem-nos devolver a confiança perdida, transferindo-a simplesmente da aleatoriedade da natureza para a certeza da eficácia tecnocientífica. Crê-se que aquilo que a natureza não faz, ou faz mal, fazemo-lo nós melhor por ela. A indesmentível plasticidade do real parece ter-se assim domesticado sob as formas do controlo tecnológico. Deste ponto de vista, estamos, de facto, em vias de realizar o sonho baconiano de uma natureza mais perfeita que ela própria, e, consequentemente, em vias de depositar a nossa confiança no artifício seguro que é produto da tecnociência, frustrada que foi pela imperfeição natural, demasiado imprevisível, aleatória e multideterminada por inúmeras variáveis e com a qual só a crença numa providência sobrenatural permitia conviver. A eficácia tecnocientífica vem deste modo dar corpo a uma 
nova providência secularizada que funciona no regime do 'ver para crer' em que os resultados tecnocientíficos assumem o papel dos antigos prodígios.

Mas, tal como a retórica dos resultados não deve ser resumida a um mecanismo de censura negativa, não se infira daí que aquilo que melhor a expressa é a sideração. Decerto que o efeito de sideração é imprescindível para dar conta da retórica dos resultados e é por intermédio dele que se constrói a imagem do cientista como providenciador, a dos meios disponíveis - se alguma há - como prestidigitação e a dos resultados como prodígio. Mais, é por essa via que o fiat tecnocientífico substitui a divina providência como força interventora na história humana. Porém, tal acontece tão-só na medida em que a tecnociência se apresenta duplamente como emancipadora e legiferante, o que o efeito de sideração, tomado por si só, não deixa entrever.

O resultado aparece revestido de um carácter autoritário e prescritivo onde a tecnociência vai exaurir boa parte da sua mais recente legitimidade. O resultado faz autoridade ao impor-se com a força de um facto que varre o que então surge como a imponderabilidade das opiniões e a vã discutibilidade dos valores. O resultado prescreve na medida em que a muda - porque não-simbólica - eficácia do seu fazer eloquentemente proclama o que se deve fazer, enquanto a política, a ética, a estética, tudo o que a tecnociência não é, aparentemente titubeiam, alvitram, ponderam e enfim se atolam na impotente ignorância e na ignorante impotência de quem não sabe porque não pode e não pode porque não sabe. E note-se então: é por se apresentar como intrinsecamente emancipadora e legiferante que a tecnociência faz política, faz ética, faz tudo o que ela não é nem pode ser. Excedendo-se na prodigalização de resultados, a tecnociência exorbita-se nos usos ético-políticos, e tanto mais quanto é precisamente por intermédio dessa exorbitação que a tecnociência se oferece como instância decisória, árbitro dos conflitos ético-políticos. Seria da objectividade e da positividade do resultado que a tecnociência adquiriria a sua condição de algum modo neutral que lhe caucionaria a sua legitimidade para dirimir conflitos. Porém, a presunção de neutralidade axiológica é posta em causa quando o público não iniciado descobre, para sua grande perplexidade e escândalo, que os interesses cognitivos que conduzem a ciência são tão permeáveis às opções políticas e éticas como as correntes de opinião que se digladiam nas arenas políticas e económicas, a cujo respeito nunca se supôs, nem elas alguma vez presumiram, a neutralidade recorrentemente proclamada pelo mundo científico. Nada patenteia tanto os compromissos ético-políticos que atravessam o fazer ciência quanto o facto de a caução do científico se repartir em igual medida pelas várias partes em litígio em momentos de discussão pública: quando se vêem cientistas aduzirem, uns contra os outros, mas com igual denodo, argumentos para sustentar tanto a inocuidade como a periculosidade ambiental da incineração de resíduos tóxicos, ou quer da humanidade do embrião humano, quer do seu contrário, nos debates sobre a interrupção da gravidez.

Assim se compreende que, na esfera pública, o argumento científico prevaleça como árbitro final sempre que se trata da tomada de decisões. Vejam-se os exemplos de recurso ao argumento biológico como árbitro derradeiro nas discussões sobre a 
humanidade dos embriões e dos fetos, ou do estatuto dos comatosos ultrapassados, ou dos clones, ou da manipulação genética das células germinais e do genoma humano em geral, enfim: toda a discussão acerca do que é uma vida humana. 'Vejamos o que nos diz a biologia': a figuração do humano faz-se cada vez mais pela aferição biológica. E, precisamente, tais discussões têm lugar não já do ponto de vista daquilo que deve ser a vida boa, ou decente, como a tradição ético-política clássica tematizava o bios politikos, mas do ponto de vista da manipulabilidade biotecnológica do indivíduo humano enquanto ser vivo e na medida em que tal manipulabilidade é empreendida e decidida pela comunidade dos seus (dis?)semelhantes organizados em polis, tal como recentemente reparou Giorgio Agamben (1997).

Ora, aquilo que a manipulabilidade biotecnológica põe em jogo são resultados, não fins ou valores. O carácter prescritivo dos resultados precipita tal substituição e o caso das ciências biomédicas, que aqui utilizámos como exemplo, será porventura o mais ilustrativo e acessível, mas decerto que não é o único a poder ser invocado. A este propósito, é mister sublinhar que o processo científico é um processo definido pelos meios que utiliza - e que disponibiliza - e não pelos resultados que almeja ou que efectivamente obtém. O que de modo nenhum significa desvalorizar ou ignorar os resultados, mas tão-só redispô-los na economia discursiva da comunicação da ciência. Nesta conformidade, o que se impõe é afirmar que a tecnociência se encontra em condições de disponibilizar meios, melhor do que produzir resultados, contra a retórica que, ao privilegiar exclusivamente estes, deixa sem resposta o facto, a todos os títulos indesmentível, dos resultados inesperados e, no que de pior o inesperado tem, indesejáveis e incontroláveis.

Com efeito, é já impossível afastar o sentimento de ambivalência que prevalece generalizadamente em relação à tecnociência que, ao mesmo tempo que concita as mais elevadas expectativas positivas, precipita também os mais funestos receios:

'This is an age of scientific fantasy and scientistic cults. While scientific rationality is valued as the basis of our 'knowledge society', science is invested with magic and mystique; we expect 'magic bullets' and 'miracle cures'. (...) While we welcome technology as the key to progress and the solution to problems, we are increasingly preoccupied with risk, fearing the very technologies we most depend upon.' (Nelkin, 1995: 7)

Acontece que a retórica dos resultados bem pode ser considerada como ilusão de controlo da dinâmica tecnocientífica de cuja exterioridade não nos é já possível fazer a experiência, isto é, como ilusão de controlo do risco tecnocientífico (Beck, 2000). Dando por certo que nunca ninguém pode biograficamente ser cientista a tempo inteiro, a retórica dos resultados passa, deste modo, por ser uma forma rapidamente acessível - embora não a única - de elaboração racional da dinâmica imparável da tecnociência que de outro modo se afigura, a todos os títulos, irrestituível ao humano, demasiado humano, das aflições e das gratificações por que se pautam as vidas dos indivíduos. A apreciação sensível ou estética dos resultados da tecnociência, que 
é o efeito que tem a retórica dos resultados na percepção pública da tecnociência, é precisamente a de mais fácil acesso e aquela a que mais imediatamente recorre quem não pode já senão apreciar em termos de prazer e de dor o que escapa à ponderação dialogante, uma vez que não é pura e simplesmente possível dialogar com a hermética voz das forças sobre-humanas da tecnociência. E aí, cientistas e leigos, cientistas e divulgadores, reencontram-se numa comum perplexidade, mas, e por isso mesmo, numa mesma comunidade de problema. Isto, se bem que possa significar reconhecimento mútuo, de modo nenhum implica necessariamente o desaparecimento automático do diferendo que os opõe de modo irreconciliável:

'Scientists and journalists are negotiating the public meaning of science and technology. This terrain, today more than ever, is contested as journalists increasingly - and appropriately - probe issues of scientific responsibility and accountability, questioning the ideologies and social priorities that guide science policy decisions. The tensions between these two communities are inevitable; indeed, maintaining their differences is essential if each community is to fulfil its unique social role.' (Nelkin, 1995: 170)

\section{A retórica dos resultados no contexto da auto-regulação da ciência}

É lícito relacionar a retórica dos resultados com a tradição de auto-regulação paritária das comunidades científicas. Contra as tentativas de as submeter a instâncias de regulação externas à comunidade dos seus pares, estas costumam alegar que a racionalidade necessária para fazerem a ciência que fazem é igualmente bastante para avaliarem eticamente o modo como fazem ciência e que aos não iniciados no método científico está vedado avaliarem a boa prática científica, em virtude da incompetência que caracteriza a sua situação de leigos. Isto acontece de modo particularmente notório com a classe médica, mas generaliza-se a todas as comunidades científicas quando, por exemplo, se trata de avaliar os riscos decorrentes das actividades científicas, nomeadamente a investigação. É este género de argumentos que mais tem sido esgrimido contra as éticas da precaução e as éticas da responsabilidade, na linha de Hans Jonas (1994).

Os discursos legitimadores da autoridade ético-política e da representatividade social da ciência não podem já praticar a antiga falácia naturalista, mas substituíram-na por um novo tipo de falácia, uma falácia propriamente artificialista. Nesta, não se trata já da passagem automática dos enunciados descritivos, respeitantes a um estado de coisas na natureza, a enunciados prescritivos no campo social, falácia esta de que a reflexão filosófica se ocupa desde David Hume até G. E. Moore (1999) e Karl-Otto Apel (2000). Trata-se, antes, da identificação do estado de coisas alterado, o poder-ser - o resultado da manipulação tecnocientífica - com o estado de coisas ideal, o dever-ser de uma 'natureza mais perfeita que a própria natureza' da ambição baconiana. Ou seja, de atribuir valor prescritivo aos próprios produtos da tecnociência. Por outras palavras ainda, trata-se da tendência para considerar todo o possível um 
existente e que vale pelo simples facto de ser possível, o que mais não faz do que exprimir, por outros termos, a fórmula do imperativo tecnológico que impõe que tudo o que é possível seja desejável. Por aí se opera a passagem do facto ao valor, da ciência à boa ciência, que os cientistas vulgarmente se comprazem em sustentar que doravante não errará onde outrora a ciência se equivocou, não por ter sido má, mas por ainda ser pouca, sempre em vias de ser mais ela própria, isto é, de saber melhor e poder mais, assim positivamente se libertando, e à humanidade sofredora, de tudo quanto (ainda) não é ela. Não é outra a racionalidade tecnocrática, de que a retórica dos resultados constitui, em última análise, um dos avatares. Com efeito, a retórica dos resultados, nos discursos da comunicação da ciência, não deixa de reflectir a atribuição de valor prescritivo, pelos próprios cientistas e frequentemente antes de mais ninguém, aos resultados da ciência que praticam. Daí o extremo embaraço dos cientistas quando confrontados com aquilo que aos olhos do público leigo só pode ser o fracasso e que de facto é a própria imprevisibilidade e incerteza inerente ao risco que comporta o processo de criação científica. Para justificar o fracasso, demonstrar a razoabilidade dele, e só então e debaixo dessa pressão, é que os cientistas costumam improvisar uma explicação tenteante do modo como realmente funciona a ciência, abalançando-se a mostrá-la tal como ela se faz, que não apenas tal como idealmente se pretende que ela resulte.

Ora, a progressão cognitiva é errática, mas falar de progressão errática significa enfatizar, como compete, o carácter mais próprio da racionalidade científica, a sua revisibilidade. Na perspectiva da percepção que o público não iniciado tem da ciência, tanto como do ponto de vista da percepção que os cientistas têm do público, a revisibilidade é o calcanhar de Aquiles da ciência. Para a percepção pública vulgar, ela assinala a incompetência científica e precipita a desconfiança em relação aos cientistas; aos olhos destes, ela é aquilo que, na ciência, mais os vulnerabiliza ante o público leigo para quem os herméticos meandros do método científico só são acessíveis aos próprios membros da comunidade científica. Aí, entra em campo a representação da ciência como a única forma qualificada de gestão do risco. No discurso do cientista o problema dos resultados indesejáveis é expresso como um problema de insuficiência da própria ciência que teria ficado 'a meio caminho', ou seja, existe problema porque a intervenção tecnocientífica não foi até ao fim e não há senão que a prosseguir e consumar até ao sucesso, o qual mais não é do que a obtenção do resultado pretendido desde o início. Apresenta-se o resultado inesperado como engano provisório apenas explicável pela momentânea desatenção, a escassez de recursos técnicos ou o descaminho especulativo, em suma, pela incompetência que interrompe a progressão linear e cumulativa da aquisição cognitiva. Deste modo, mais não há que reconduzir o processo científico aos únicos que estão realmente qualificados para o prosseguir, os peritos.

A ciência progride na medida da sua abertura, não do seu fechamento em blocos estanques que se acumulariam uns sobre os outros, e procede por destruições e reconstruções incessantes, nisso consistindo a abertura que é garantia da sua progressão e o carácter mais próprio dessa progressão é a revisibilidade. Outro não é o adquiri- 
do da epistemologia contemporânea (Feyerabend, 1981, 1991; Lakatos, 1998, 1999). Os avanços cognitivos apresentam-se sobretudo como momentos de autocorrecção da dinâmica tecnocientífica e inflexão da intervenção tecnocientífica em relação às direç̧ões seguidas pelos estádios anteriores da sua evolução. No entanto, essa autocorrecção nada tem de cumulativo, antes constitui uma cadeia de reconstruções racionais que, de cada vez, obrigam a uma inflexão. A revisão de um programa tecnocientífico não é pois uma simples questão de correcção conjuntural sobre um adquirido que permanece, porquanto ela implica o pôr em causa desse adquirido e a alteração de rumo no estabelecimento de metas da investigação:

'Scientists themselves believe science to be self-correcting, because the philosophers and the historians and the scientific method have told them so. Scientists have seen no need for a code of professional conduct because they have believed that the constraints of reality, exercised through the method, have been stronger and more automatic in application than any human code could be. (...) Only if the profession convinces society of its effective ethical concerns will society allow the profession to continue to govern itself.' (Bauer, 1992: 85)

É deste modo que a retórica dos resultados contribui também, embora não baste, para que a racionalidade científica possa surgir, tanto ao olhar leigo como ao dos próprios cientistas, como algo de não problemático, de exterior ao polemos, à discutibilidade e à argumentabilidade. A tanto equivale a presunção da auto-suficiência científica, ou seja, a reivindicada capacidade de a comunidade científica se auto-regular com simples recurso à mesma racionalidade que presume conhecer com rigor e controlar com eficácia os fenómenos. Nesta perspectiva, também, a ciência só pode ser má ciência se e na medida em que se deixar instrumentalizar, isto é, quando se vir subtraída ao controlo dos próprios cientistas, cuja racionalidade intrínseca constitui garantia suficiente tanto da bondade como do rigor com que a prosseguem. O que normalmente prevalece na divulgação não é a incompatibilidade de teses científicas entre si, e, portanto, a controvérsia interna à própria racionalidade científica, mas a incompatibilidade - melhor, a incomensurabilidade - entre a discursividade delas e outros saberes, o que desloca a controvérsia para o exterior da ciência. A ciência só é verdadeiramente obrigada a discutir com o que não é ela e o que não é ela tende assim a ser representado como o ponto de vista da impertinência que ignora e perante a qual a ciência se condescende no debate, tão-só para melhor assumir o paternal papel da correcção pedagógica.

Aqui reencontramos com incómoda frequência o deplorável papel dos cientistas que se dedicam à divulgação e que filosofam de maneira pós-prandial sobre o que supõem ser as implicações extracientíficas da sua ciência. É comum o penoso espectáculo de autocomplacente ignorância e jovial presunção do cientista lisonjeado pelos meios de comunicação que em puro disfrute diletante opina sobre política, que não só a científica, faz uma perninha nas humanidades, morde na ética e belisca o direito, 
com os quais se compraz em fazer uma leitura corroboratória da identificação estratégica dos interesses da ciência - porventura legítimos em si mesmos e regionalmente, mas não universalmente - com os interesses da sociedade em geral.

\section{A retórica dos resultados no contexto da retórica da ciência}

Assim como relacionámos a retórica dos resultados com a índole da tecnociência moderna e com a tradição de auto-regulação das comunidades científicas, há que situá--la agora em relação a uma outra retórica que a antecede e que é intrínseca ao próprio discurso científico, no que acompanhamos Alan Gross: 'We can argue that scientific knowledge is not special, but social; the result not of revelation, but of persuasion' (1996: 20). A retórica seria co-extensiva a todo o discurso científico: 'A complete rhetoric of science must avoid this accusation: after analysis, something unrhetorical remains, a hard 'scientific core" (p. 33). Segundo Gross, é a própria retórica da ciência que permite ao cientista fazer a sua peculiar leitura da revisibilidade científica:

“(...) the set of all scientific papers undermines the myth that each paper instantiates. First, this set exhibits terminological instability, the sine qua non of opinion; second, it undermines the certainty of scientific knowledge, for what science routinely creates, it routinely overturns; finally, this set proclaims successive - and often contradictory - truths, a history hard to reconcile with any coherent notion of progress (...) by means of its form alone, each scientific paper, each act of significant science, routinely conveys, along with its particular conclusions, the justification of the enterprise whose raison d'être is reaching such conclusions' (p. 96).

Nesta conformidade, Gross adianta que, do ponto de vista retórico, a descoberta científica deve com propriedade ser descrita como invenção.

'Discovery is an honorific, not a descriptive term (...). The term invention, on the other hand, captures the historically contingent and radically uncertain character of all scientific claims, even the most successful. If scientific theories are discoveries, their unfailing obsolescence is difficult to explain; if these theories are rhetorical inventions, no explanation of their radical vulnerability is necessary.' (p. 7).

Numa linha que, neste ponto, é grandemente devedora do adquirido da história da ciência e da epistemologia, Gross prossegue:

'Although each scientific procedure is doubtless based on argument, we can discover this only by means of a diligent search into the scientific past. For scientists, however, science has no past - or, rather, no past that does not wholly suit its present purposes. It is this absence, then, that nurtures the useful illusion: for scientists, the results of science depend not on argument but on nature herself.' (Gross, 1996: 32) 
Na racionalidade científica, logos, ethos e pathos encontram-se indissoluvelmente ligados. Com efeito, '(s)cientists are not persuaded by logos alone; science is no exception to the rule that the persuasive effect of authority, of ethos, weighs heavily' (p. 12). Por conseguinte: 'From a rhetorical point of view, the high esteem bestowed upon science gives its communications a built-in ethos of especial intensity' (p. 21). Por sua vez, a ciência não é alheia ao pathos: '(...) tropes like irony and hyperbole do appear regularly in scientific reports, belying the alleged reportorial nature of these texts (...)' (p. 18). 'Emotional appeals are clearly present in the social interactions of which science is the product' (p. 14). A retórica dos resultados repete, no campo da comunicação da ciência, a articulação entre logos, ethos e pathos já preexistente na retórica do próprio discurso científico.

\section{A retórica dos resultados no contexto da (i)literacia científica}

Porventura compreensível entre os públicos menos familiarizados com o fazer da ciência, a retórica dos resultados não deve no entanto ser entendida primordialmente como um problema dos públicos - ainda que neles se reflictam eventualmente as suas mais dramáticas consequências - mas sobremaneira como um problema dos divulgadores. Traço distintivo da retórica dos resultados é justamente o seu carácter vertical: muito mais que decorrer necessariamente da iliteracia científica dos públicos, que o modelo linear proverbialmente pressupunha, ela é comum não só aos profissionais da divulgação que não pertencem à comunidade de pares científicos, mas aos próprios cientistas que fazem da divulgação quer uma carreira paralela, quer uma incursão mundana fora da academia. Acontece que a dependência crescente da ciência de tecnologia sofisticada, que é ao mesmo tempo extremamente cara e sujeita a regulação, e a necessidade de financiamentos levaram os cientistas a privilegiarem uma estratégia de divulgação que sublinha os êxitos e a segurança dos processos que obtêm resultados:

'Too often science is presented as an arcane activity outside and above the
sphere of normal human understanding, and therefore beyond our control.
Too often the coverage is promotional and uncritical, encouraging apathy, a
sense of impotence, and the ubiquitous tendency to defer to expertise. Focusing
on individual accomplishments and dramatic or controversial events, journalists
convey little about the sociology of science, the structure of scientific institutions,
or the daily routines of research. We read about the results of research and the
stories of success, but not about the process, the dead ends, the wrong turns.'
(Nelkin, 1995: 162)

Na opinião de Nelkin, na comunicação da ciência, e particularmente na comunicação das ciências médicas e biológicas que têm uma particular repercussão emocional no público por estarem mais próximas de factos dramáticos da sua vida quotidiana, é frequente a imagética substituir o conteúdo, as notícias centrarem-se na 
competição científica e tecnológica entre indivíduos, instituições e países, e a investigação ser coberta como uma série de acontecimentos espectaculares descritos com hipérboles que visam sobretudo elevar as suas expectativas e o seu interesse do público, mas que rapidamente passam da promoção à execração quando as expectativas são frustradas, de tal modo que ' $(t)$ he images of science and technology in the press (...) are often shifting, reflecting current fashions and prevailing fears. Today's exaggerated promises - of new fixes, new devices, new cures - become tomorrow's sensationalized problems' (Nelkin, 1995: 63).

$\mathrm{O}$ que acaba por ser encorajado na comunicação da ciência que privilegia os resultados é aquilo a que Pierre Bourdieu chamou um dia o 'fast thinking' (Bourdieu, 1997), contra o qual os próprios profissionais da comunicação facilmente se deparam desprovidos e até impotentes:

'While most journalists try to avoid a sensationalist and titillating style, they do tend to magnify events and to overestimate if not sensationalize their significance. Research applications, after all, make better copy than qualifications. 'Revolutionary breakthroughs' are more exciting than 'recent findings'. And controversies are more newsworthy than routine events.' (Nelkin, 1995: 112-113)

Em última análise, a retórica dos resultados não informa nem forma. Faz do público uma audiência de curiosos: lá onde a curiosidade científica desdobra o desconhecido na procura infinita que mais genuinamente caracteriza a ciência, a retórica dos resultados devolve o fechamento de um produto fungível que enclausura o consumidor no labiríntico horizonte da satisfação das suas necessidades incessantemente realimentadas. Idêntica pedagogia do usufruto não criativo sustenta boa parte dos materiais educativos dirigidos a públicos em idade escolar, as gerações que se pretende 'educar para a ciência' - atente-se especialmente em tudo quanto respeita às novas tecnologias da comunicação.

Surpreendentemente, ou talvez nem tanto, a retórica dos resultados prevalece igualmente, e com espantosa frequência, nos eventos oficiais das políticas públicas de promoção da cultura científica, organizados com o concurso dos próprios cientistas e selados aos mais altos níveis das instâncias de decisão. Sem ser inelutável, a retórica dos resultados diz respeito à representação que fazem da actividade científica tanto o público não iniciado na metodologia científica como os próprios cientistas que, sendo-o, passam também a ser o primeiro público da ciência que fazem, a partir do momento em que encetam o processo de a divulgar. Quando se abalançam a fazer divulgação, os cientistas principiam a volver sobre a ciência o olhar quotidiano em que se exprimem os valores, os móbeis e as expectativas (negativas ou positivas) do mundo social que se encontra a montante e a jusante do fazer ciência.

É na linguagem quotidiana que se exprime a retórica dos resultados e não já na linguagem formal que vigora portas do laboratório adentro. Ao anteciparem, imaginariamente, o que pode ser a forma mentis do público ideal, num esforço de assimilação 
dela pelo discurso vulgarizador, por mor do imperativo de traduzir para a linguagem quotidiana o hermetismo formal da linguagem científica, os cientistas são facilmente presa das suas próprias representações da ciência, que de seguida transmitem ao público como se se tratasse da ciência 'tal qual se faz', quando é da ciência tal qual ela é representada pelos cientistas que realmente se trata. Uma vez mais, isto acontece inclusivamente nos próprios manuais escolares elaborados com o concurso dos cientistas e que visam iniciar na ciência um público entre o qual se espera vir um dia a recrutar aqueles que mais tarde engrossarão as fileiras da ciência:

'Through learning textbook science, one is misled about the nature of scientific activity by learning only about relatively successful science, the things that have remained within science up to the present. In scientific texts, one hardly ever encounters the phenomenon of unsuccessful science, and yet history teaches that the science being done at any given time will largely be discarded, even in the short space of a few years, as unsuccessful' (Bauer, 1992: 11)

O cientista não ganha em objectividade, pelo facto de o ser, ao falar da ciência que ele próprio faz. Ao falar dela, fala não do ponto de vista de quem está no seu interior - no laboratório - mas do ponto de vista de uma comunidade maior que ela - o mais elevado interesse da sociedade, ou da humanidade -, tão exterior ao laboratório como o público não iniciado. Isto não significa, porém, que o laboratório seja asséptico aos interesses prevalecentes no mundo extra-científico, como muito bem o demonstraram as pesquisas de Bruno Latour (1995, 1996; Latour e Woolgar, 1995). Muito pelo contrário, é a comunidade científica que representa para si própria e apresenta ao olhar alheio, como neutrais e apolíticos os seus próprios interesses cognitivos no momento de fazer ciência, tão-só se limitando ela a servir o bem comum. O olhar dos cientistas sobre a ciência que fazem torna-se assim congenial ao olhar do público receptor que a consome, ambas convergindo num horizonte de expectativas comum e votado a um mesmo uso social da ciência. Não se trata de uma debilidade corrigível do cientista, aquilo que o transforma imediatamente em público de si mesmo mal pretende metamorfosear a sua ciência-ciência em ciência-cultura.

De um ponto de vista wittgensteiniano (Wittgenstein, 1987), a passagem da linguagem formal da ciência à linguagem quotidiana da vulgarização mais não seria que uma mudança de jogo de linguagem. Na verdade, o cientista não pode escapar ao modo narrativo originário da linguagem humana, que a tradição hermenêutica, e particularmente as análises de Paul Ricoeur (1985), mostra ser comum tanto à efabulação quotidiana como à explicação científica, ambas enformadas que são pelo esquema finalista de todo o agir. Ricoeur mostrou há muito como o modelo narrativo de todos os textos que conhecemos até hoje é a narrativa mítica. A sua racionalidade foi, por sua vez, reabilitada no campo da antropologia por Claude Lévy-Strauss, para quem um mito não é uma mera história, mas um modelo lógico capaz de ultrapassar uma contradição fundamental. É neste sentido que, ao estudar a retórica da ciência, Alan Gross se permite falar do artigo científico como um mito (Gross, 1996: 95). Nos 
tempos que correm, não é difícil tropeçar em exemplos: 'In the 1990s research on embryo cloning, pregnant postmenopausal women, and genetically engineered pigs is drawing readers and selling magazines. And journalists play up the biggest collider, the newest techniques of bioengineering, the riskiest technologies.' (Nelkin, 1995:1)

Jean-Marc Lévy-Leblond (1996: 20-23) falou a este propósito de um paradoxo cultural que consiste no facto de quanto mais se dissemina a tecnociência na vida quotidiana, mais opacos e inacessíveis se tornam os seus produtos para os respectivos utilizadores, de tal modo que os objectos técnicos omnipresentes no mundo actual se apresentam aos nossos olhos com a carga de mistério que têm os buracos negros no espaço. Este fenómeno não diz respeito apenas à relação entre a tecnociência e o público, antes se nota no próprio seio da ciência, nas relações entre cientistas. Com efeito, a hiperespecialização e a fragmentação disciplinar a que conduziu o desenvolvimento científico faz dos cientistas ignorantes especializados que, colegas de diferentes disciplinas, se comportam uns em relação aos outros como o público leigo em relação à ciência em geral.

Há que dizer que, neste sentido, a própria dinâmica da produção cognitiva decorrente do desenvolvimento tecnocientífico produz iliteracia, segrega-a regularmente, à medida que a linguagem científica se vai distanciando da linguagem quotidiana e se multiplicando no seu interior em outros tantos hermetismos disciplinares, subdisciplinares, microdisciplinares. $\mathrm{O}$ que nos obrigaria a concluir que a abertura da ciência a novas disciplinas produz o seu próprio fechamento em novas linguagens estanques, por vezes até ao ponto da incomensurabilidade. A este respeito, Felt indica-nos que há pelo menos duas ordens de razões que contradizem esta imagem de uma ciência 'aberta':

'Em primeiro lugar, o processo de institucionalização, diferenciação e especialização no sistema científico criou ainda maiores barreiras de acesso para aqueles que não possuem pré-requisitos educativos formais. (...) Em segundo lugar, embora tenhamos testemunhado no decorrer do século XX, uma multiplicação dos media abrindo novos espaços onde a ciência encontra o público (...), isto não conduziu paradoxalmente a uma aproximação entre a ciência e o público (...). Antes pelo contrário, quanto mais sofisticada e densa se tornou a troca de informação, mais privilegiadas se tornaram as pessoas que já possuíam um capital intelectual inicial considerável - um fenómeno a que se chamou a disparidade crescente do conhecimento.' (Felt, 2000a: 265-266)

Ora, justamente aquilo que entendemos por retórica dos resultados deve ser tido como efeito de censura positiva dessa iliteracia que a dinâmica tecnocientífica segrega por assim dizer naturalmente: os não iniciados numa área específica da especialização científica, tal como os não iniciados no processo científico em geral, propendem a transformar os produtos da tecnociência no eixo da sua própria representação do processo que lhes deu origem. Incompreensível, o processo só pode ser abordado pelos respectivos resultados. Eles tornam-se assim naquilo que Wolfgang Iser (1978) 
chamou o leitor implícito de um texto, o conjunto de indicações que um texto dá para a sua própria leitura. O resultado implica o leitor no processo, tornando-se instrução de leitura deste, pois é a única via de acesso a ele que se oferece de forma imediata ao leitor não iniciado. Na retórica dos resultados dos textos de comunicação da ciência, o resultado é o operador de leitura do processo científico. E a consequência maior deste fenómeno é que, tanto ao publicitar-se como ao ser percebida como produtora de resultados, que ela indubitavelmente acaba por ser, a ciência censura-se positivamente como detentora e disponibilizadora de meios, que ela não menos indubitavelmente começa por ser, antes de poder produzir qualquer resultado.

\section{Referências}

Agamben, G. (1997) Homo Sacer. Le Pouvoir souverain et la vie nue. Paris: Éditions du Seuil. Apel, K.-O. (2000) Transformação da Filosofia, I e II. São Paulo: Edições Loyola.

Bauer, H. (1992) Scientific Literacy and the Myth of the Scientific Method. Urbana \& Chicago: University of Illinois Press.

Beck, U. (2000) Risk Society. Towards a New Modernity. London: Sage.

Bourdieu, P. (1997) Sobre a Televisão. Oeiras: Celta Editora.

Felt, U. (2000a) 'A Adaptação do Conhecimento Científico ao Espaço Público' in Gonçalves, M. (coord.) Cultura Científica e Participação Pública. Oeiras: Celta Editora, pp. 265-288.

Felt, U. (2000b) 'Why Should the Public 'Understand' Science? A Historical Perspective on Aspects of the Public Understanding of Science' in Dierkes, M. \& von Grote, C. (eds.) Between Understanding and Trust: The Public, Science and Technology. Amsterdam: Harwood Academic Publishers, pp. 7-38.

Feyerabend, P. (1991) Adeus à Razão. Lisboa: Edições 70.

Feyerabend, P. (1981) Contra el Metodo. Barcelona: Ariel.

Gieryn, T. (1999) Cultural Boundaries of Science. Credibility on the Line. Chicago \& London: The University of Chicago Press.

Gieryn, T. (1994) 'Boundaries of Science' in Jasanoff, S., Markle, G., Petersen, J. \& Pynch, T. (eds.) Handbook of Science and Technology Studies. Thousand Oaks: Sage Publications, pp. 393-443.

Gross, A. (1996) The Rhetoric of Science. Cambridge \& London: Harvard University Press.

Hottois, G. (1999) Essais de Philosophie Bioéthique et Biopolitique. Paris: Vrin.

Hottois, G. (1996) Entre Symboles et Technosciences. Un Itinéraire Philosophique. Paris: Champ Vallon.

Hottois, G. (1992) O Paradigma Bioético. Lisboa: Edições Salamandra.

Hottois, G. (1984a) Pour une Éthique dans un Univers Technicien. Bruxelles: Éditions de l'Université de Bruxelles.

Hottois, G. (1984b) Le Signe et la technique. Paris: Aubier-Montaigne.

Iser, W. (1978) The Act of Reading. A Theory of Aesthetic Response. London: Routledge \& Kegan Paul. Jeanneret, Y. (1994) Écrire la science. Formes et enjeux de la vulgarisation. Paris: Presses Universitaires de France.

Jonas, H. (1994) Ética, Medicina e Técnica. Lisboa: Vega.

Lakatos, I. (1999) Falsificação e Metodologia dos Programas de Investigação Científica. Lisboa: Edições 70.

Lakatos, I. (1998) História da Ciência e suas Reconstruções Racionais. Lisboa: Edições 70.

Latour, B. (1996) Petites leçons de sociologie des sciences. Paris: Éditions La Découverte.

Latour, B. (1995) La Science en action. Paris: Gallimard.

Latour, B. \& Woolgar, S. (1995) La Vida en el Laboratorio. La Construcción de los Hechos Científicos. Madrid: Alianza Editorial.

Lévy-Leblond, J. M. (1996) La Pierre de touche. La Science à l'épreuve... Paris: Gallimard.

Moore, G. (1999) Principia Ethica. Lisboa: Fundação Calouste Gulbenkian. 
Nelkin, D. (1995) Selling Science. How the Press Covers Science and Technology. New York: W. H. Freeman and Company.

Ricoeur, P. (1985) Temps et Récit, I, II, III. Paris: Éditions du Seuil.

Royal Society (1985) The Public Understanding of Science. London: The Royal Society.

Wittgenstein, L. (1987) Tratado Lógico-filosófico. Investigações Filosóficas. Lisboa: Fundação Calouste Gulbenkian. 